Virtuelle Lebenswelten 



\section{Virtuelle Lebenswelten}

Körper - Räume - Affekte

Herausgegeben von

Stefan Rieger, Armin Schäfer und Anna Tuschling 
Gedruckt mit freundlicher Unterstützung der Ruhr-Universität Bochum und der Fakultät für Philologie der Ruhr-Universität Bochum

ISBN 978-3-11-063486-0

e-ISBN (PDF) 978-3-11-063812-7

e-ISBN (EPUB) 978-3-11-063513-3

DOI https://doi.org/10.1515/9783110638127

\section{(cc) BY-NC-ND}

Dieses Werk ist lizensiert unter einer Creative Commons Namensnennung - Nicht-kommerziell Keine Bearbeitung 4.0 International Lizenz. Weitere Informationen finden Sie unter http://creativecommons.org/licenses/by-nc-nd/4.0/.

\section{Library of Congress Control Number: 2020943901}

\section{Bibliografische Information der Deutschen Nationalbibliothek}

Die Deutsche Nationalbibliothek verzeichnet diese Publikation in der Deutschen Nationalbibliografie; detaillierte bibliografische Daten sind im Internet über http://dnb.dnb.de abrufbar.

(C) 2021 Stefan Rieger, Armin Schäfer und Anna Tuschling, publiziert von Walter de Gruyter $\mathrm{GmbH}$, Berlin/Boston.

Dieses Buch ist als Open-Access-Publikation verfügbar über www.degruyter.com.

Coverabbildung: Grafik von Niklas Münchbach

Satz: Integra Software Services Pvt. Ltd.

Druck und Bindung: $\mathrm{CPI}$ books $\mathrm{GmbH}$, Leck

www.degruyter.com 